\title{
INFLUÊNCIA DA PRESENÇA DE POROS DEVIDO À INCORPORAÇÃO DE AR NA DURABILIDADE DE CONCRETO AUTOADENSÁVEL FRENTE À CARBBONATAÇÃO
}

\author{
ROCHA, GUSTAVO LOPES \\ Graduando em Engenharia Civil \\ Universidade de São Paulo \\ São Paulo; Brasil \\ gustavo.lopes.rocha@usp.br
}

\author{
FERREIRA, FERNANDA G. S. \\ Professora Doutora \\ Universidade Federal de São Carlos \\ São Paulo; Brasil \\ fgiannotti@ufscar.br
}

\author{
CASTRO, ALESSANDRA L. \\ Professora Doutora \\ Universidade de São Paulo \\ São Paulo; Brasil \\ alcastro@sc.usp.br
}

\section{RESUMO}

A durabilidade do concreto está relacionada com a dificuldade de penetração de agentes agressivos que, por sua vez, é influenciada pelas características dos poros presentes no material. Quando sujeito a um gradiente de pressão, o concreto tende a permitir a passagem de um fluido, sendo tal propriedade a permeabilidade. A capilaridade é o mecanismo de transporte de líquidos devido à tensão superficial nos poros do concreto, de maneira que quanto menor o diâmetro dos capilares, maiores as pressões dos mesmos. O fenômeno da carbonatação, um dos principais agentes iniciadores da corrosão da armadura no concreto, é originado pela penetração do gás carbônico no concreto por meio do mecanismo e propriedade descritos anteriormente. Neste contexto, o presente trabalho busca analisar a influência dos poros presentes em concreto autoadensável com aditivo incorporador de ar frente à ação da carbonatação. Para isso, foram produzidos dois traços de concreto autoadensável, com resistência característica à compressão de $40 \mathrm{MPa}(\mathrm{C} 40)$, ambos com ar incorporado (com teores de ar de $9 \%$ e 15\%). Os corpos de prova foram submetidos à carbonatação natural (ambiente de laboratório) e acelerada (câmara de carbonatação), sendo realizadas medidas da profundidade de carbonatação e absorção de água por capilaridade após 28, 91 e 180 dias de exposição. Verificou-se que existe um limite de incorporação de ar que passa a ser prejudicial à durabilidade do concreto: enquanto o concreto com $9 \%$ de ar incorporado mostrou-se resistente à ação da carbonatação, o concreto com $15 \%$ de ar mostrou-se deficiente em relação à durabilidade.

Palavras-chave: concreto autoadensável, durabilidade, carbonatação, porosidade, aditivo incorporador de ar.

\section{ABSTRACT}

The durability of concrete is related to the difficulty of aggressive agents penetration which, in turn, is influenced by the characteristics of the pores present in the material. When subjected to a pressure gradient, concrete tends to allow the flow of a fluid, being such property the permeability. Capillarity is the mechanism of the liquid transport due to the surface tension in the concrete pores, so that the smaller the capillaries diameters, the higher their pressures. The carbonation phenomenon, one of the main initiators of reinforcement corrosion in concrete, is caused by the penetration of carbon dioxide in concrete through the mechanism and property described above. In this context, the present paper aims to analyze the influence of pores present in self-compacting concrete with air-entraining admixture to the action of carbonation. For this, two self-compacting concrete mix design, with characteristic compressive strength of $40 \mathrm{MPa}$ (C40), were produced, both with air incorporated (with air contents of $9 \%$ and 15\%). The specimens were subjected to natural (laboratory environment) and accelerated (carbonation chamber) carbonation, being measured the carbonation depth and water absorption by capillarity after 28, 91 and 180 days of exposure. It was found that there is a limit of air incorporation that becomes detrimental to the durability of concrete: while the concrete with $9 \%$ of air incorporated was resistant to the action of carbonation, the concrete with $15 \%$ of air was deficient regarding the durability.

Keywords: self-compacting concrete, durability, carbonation, porosity, air entraining admixture. 


\section{INTRODUÇÃO}

As normas atuais de projeto de estruturas de concreto contemplam, em questão de durabilidade, a influência da porosidade na penetração de agentes agressivos indiretamente, indicando a adoção de valores máximos para a relação água/cimento e de espessuras mínimas de cobrimento da armadura para cada classe de agressividade ambiental (ABNT, 2014). Contudo, também é conhecido que, quanto menor a velocidade de penetração dos agentes agressivos no concreto, ou seja, quanto mais difícil é a penetração dos mesmos no concreto, mais tempo levará até que atinjam a armadura (OLLIVIER et al., 2014; RIBEIRO et al., 2014). Portanto, a durabilidade não é apenas questão de espessura de cobrimento, mas também da estrutura dos poros presentes no concreto, pois os poros interconectados são os que efetivamente participam do transporte de substâncias no interior do material (ISAIA et al., 2011).

O sistema de poros interconectados do concreto tende a permitir a passagem de um fluido quando sujeito a um gradiente de pressão, sendo essa propriedade a permeabilidade (ISAIA et al., 2011; OLLIVIER et al., 2014). Características como o volume e dimensão dos poros, grau de interconexão entre os poros e abertura dos poros na superfície externa influenciam diretamente na permeabilidade do concreto (BERTOLINI, 2010). O mecanismo de transporte do fluido, quando ocorre devido à tensão superficial presente nos poros capilares do concreto (devido ao gradiente de umidade) é denominado capilaridade. A absorção capilar ocorre em maior intensidade quanto maior for a diferença do gradiente de umidade e quanto menor for o diâmetro dos capilares. A relação com o diâmetro dos capilares se dá pois quanto menor sua dimensão, maior a tensão superficial e, com isso, maiores as pressões que ocorrem a favor da ascensão do fluido (BERTOLINI, 2010; RIBEIRO et al., 2014). Assim, a absorção capilar é um fator de considerável importância na entrada de agentes agressivos devido ao transporte por água.

A fim de evitar o aprisionamento de ar no material e facilitar a execução de estruturas de concreto, é recomendado o uso de concreto autoadensável (CAA) para obras com taxa de armadura elevada ou caso existam formas complexas, que fazem com que seja difícil o acesso de vibradores para o adequado adensamento do material (GOMES; BARROS, 2009). O CAA necessita da adição de substâncias químicas tensoativas (que melhoram a trabalhabilidade sem necessitar de aumento na relação água/cimento) para otimizar suas propriedades de fluidez, autoadensamento e preenchimento de toda a forma sob ação apenas do seu peso próprio. Os aditivos tensoativos ou surfactantes englobam os aditivos incorporadores de ar e os redutores de água (MEHTA; MONTEIRO, 2014). Os tensoativos agem aumentando a estabilidade na interface ar-água e sólido-água e, com isso, a maior tensão superficial neutraliza a tendência das bolhas de se romperem ou unirem (DOLCH, 1995). A incorporação de ar pode ser benéfica frente à durabilidade, pois a formação de bolsas de ar diminuem o fluxo de água através do concreto (BAUER, 2000).

Dado que o concreto é um material intrinsicamente poroso, para garantir a durabilidade do concreto armado, a velocidade de penetração de agentes deletérios ao sistema deve ser controlada, como por exemplo a velocidade de penetração de $\mathrm{CO}_{2}$. A carbonatação afeta os concretos de forma favorável, colmatando os poros e tornando o material mais compacto, aumentando assim a resistência e diminuindo a permeabilidade (SINGH; SINGH, 2016). Porém, para o concreto armado, devido à redução de pH causada pela carbonatação o efeito é deletério para a armadura (BAUER, 2000).

De acordo com os experimentos de Singh e Singh (2016), o incremento na porosidade do concreto causa o aumento da profundidade de carbonatação. Já Zhang et al. (2018) demonstraram que existe um acréscimo na resistência de penetração de agentes agressivos conforme o teor de ar incorporado aumenta até alcançar um teor limite, além do qual resultados opostos são observados.

Assim, diante da problemática de durabilidade envolvendo porosidade e permeabilidade do concreto, este artigo busca analisar a influência dos poros presentes em concreto autoadensável com aditivo incorporador de ar frente à ação da carbonatação.

\section{METODOLOGIA}

Inicialmente, foi realizado o estudo de dosagem para produzir o concreto autoadensável de classe C40 (40 MPa) com teores de ar incorporado de $9 \%$ e $15 \%$ em relação à massa do concreto fresco. Os teores adotados foram definidos por Ferreira (2019) com base nas recomendações de práticas de execução de paredes de concreto moldadas no local. As propriedades de autoadensabilidade no estado fresco foram verificadas segundo as especificações da NBR 158231:2017 (ABNT, 2017). Os materiais constituintes das misturas de concreto produzidas foram: 
- Cimento Portland composto com escória, com resistência à compressão mínima aos 28 dias de idade igual a $32 \mathrm{MPa}$ - CPII E 32;

- Areia natural de origem quartzosa com granulometria média e fina;

- $\quad$ Agregado graúdo de origem basáltica, com dimensão máxima característica de 9,5 mm;

- Sílica ativa derivada do processo de produção do silício metálico ou ferro silício;

- Fíler calcário de malha 325;

- Aditivo superplastificante à base de policarboxilatos - ADVA CAST 525;

- $\quad$ Aditivo incorporador de ar - DARAFILL EXP 300;

- Água proveniente da rede de abastecimento local.

Após a desmoldagem, realizada 24 hs após o fim da concretagem, os corpos de prova permaneceram em câmara úmida por 14 dias e, após este período foram submetidos ao pré-condicionamento por 21 dias a fim de estabilizar a umidade interna do material. Em seguida, as amostras foram expostas aos ambientes natural e acelerado para determinação da profundidade de carbonatação. $\mathrm{O}$ ambiente natural foi o próprio ambiente de laboratório (temperatura e umidade ambientes relativas à São Carlos/SP entre os meses de dezembro de 2018 e julho de 2019), enquanto o acelerado foi a câmara de carbonatação (concentração de $\mathrm{CO}_{2}$ de aproximadamente $15 \%$ e umidade relativa do ar entre $70 \%$ e $80 \%$ ) (ROCHA; FERREIRA; CASTRO, 2019). Além disso, foram mantidos corpos de prova em câmara úmida, sem exposição à carbonatação, para efeitos de comparação do comportamento do material em termos de durabilidade.

Para verificação das propriedades e características das amostras, foram realizados ensaios de absorção de água por capilaridade logo após o fỉm do pré condicionamento e, para determinação da profundidade de carbonatação e absorção de água por capilaridade, nas idades de 28, 91 e 180 dias contados a partir da entrada dos corpos de prova na câmara de carbonatação. Para o ensaio de profundidade de carbonatação, as amostras foram submetidas à tração por compressão diametral e, após rompidas, foi aspergida solução de fenolftaleína na superfície fraturada. Para o ensaio de absorção de água por capilaridade foram seguidas as diretrizes da NBR 9779:2012 (ABNT, 2012).

\section{RESULTADOS E DISCUSSÕES}

\subsection{Traço utilizado}

Para ambos os traços adotou-se uma relação água/cimento $(\mathrm{a} / \mathrm{c})$ de 0,45 . O consumo de materiais pode ser visualizado na Tabela 1, enquanto as características de autoadensabilidade no estado fresco são apresentadas na Tabela 2. Detalhes do estudo de dosagem estão disponíveis em Ferreira (2019).

Tabela 1 - Traços utilizados - consumo de materiais $\left(\mathrm{kg} / \mathrm{m}^{3}\right)$

\begin{tabular}{c|c|c}
\hline Material & C40-A9 & C40-A15 \\
\hline Cimento & 333 & 314 \\
\hline Sílica ativa & 34 & 32 \\
\hline Fíler calcário & 166 & 157 \\
\hline Água & 150 & 142 \\
\hline Superplastificante & 2,629 & 2,479 \\
\hline Incorporador de ar & 0,333 & 0,628 \\
\hline Areia fina & 281 & 265 \\
\hline Areia média & 420 & 396 \\
\hline Brita & 823 & 776 \\
\hline
\end{tabular}

Tabela 2 - Traços utilizados - características de autoadensabilidade no estado fresco

\begin{tabular}{c|c|c|c|c}
\hline \multirow{2}{*}{ Ensaio } & \multicolumn{2}{|c|}{ C40-A9 } & \multicolumn{2}{c}{ C40-A15 } \\
\cline { 2 - 4 } & Resultado & Classe & Resultado & Classe \\
\hline Espalhamento $(\mathrm{mm})$ & 560 & SF 1 & 575 & SF 1 \\
\hline Viscosidade plástica aparente $-\mathrm{T}_{500}(\mathrm{~s})$ & 1,24 & VS 1 & 1,53 & VS 1 \\
\hline Índice de estabilidade visual & Estável & IEV 0 & Estável & IEV 0 \\
\hline Anel J (mm) & 25 & PJ 1 & 10 & PJ 1 \\
\hline Caixa L (H2/H1) & 0,86 & PL 2 & 0,76 & PL 2 \\
\hline Funil V (s) & 5,86 & FV 1 & 3,41 & FV 1 \\
\hline Coluna de segregação (\%) & 10,3 & SR 2 & 4,5 & SR 2 \\
\hline
\end{tabular}


Em relação aos resultados dos ensaios de autoadensabilidade dos traços utilizados, todos os parâmetros estão de acordo com a definição de CAA estabelecida na NBR 15823-1:2017 (ABNT, 2017). O espalhamento dos traços ficou abaixo do limite estabelecido para o estudo de dosagem, mas ainda assim possuem espalhamento que os enquadra na categoria SF1. Quanto ao ensaio de caixa L, o traço C40-A15 ficou abaixo do limite, indicando deficiência da habilidade passante. No entanto, cabe ressaltar que não foi feito ajuste no teor de aditivo superplastificante quando da adição do aditivo incorporador de ar, de maneira a verificar a influência da adição desse aditivo sobre as propriedades do concreto no estado fresco.

Os traços utilizados atingiram valores de massa especifica no estado fresco correspondentes aos teores de ar incorporado de 9\% e 15\%, determinado pelo método gravimétrico conforme NBR 9833:2008 (ABNT, 2008). Assim, o traço com $9 \%$ de ar incorporado será denominado C40-A9, enquanto o traço com 15\% de ar incorporado será identificado como C40-A15.

\subsection{Absorção de água por capilaridade}

Para os corpos de prova que permaneceram em cura úmida, em ambiente de laboratório e em câmara de carbonatação, foi realizado o ensaio de absorção de água por capilaridade nas diferentes idades, conforme a NBR 9779:2012 (ABNT, 2012). Os corpos de provas utilizados nos ensaios foram cilíndricos, com $100 \mathrm{~mm}$ de diâmetro e $200 \mathrm{~mm}$ de altura, sendo utilizados 3 amostras em cada idade no ensaio de cada mistura. As idades de ensaio são referentes à entrada dos corpos de prova na câmara de carbonatação, portanto $0 \mathrm{~d}$ é equivalente ao final do pré-condicionamento e $28 \mathrm{~d}$, $91 \mathrm{~d}$ e $180 d$ as idades das amostras a partir disso (tempo de exposição). Para a comparação entre as idades analisadas, serão apresentados os dados obtidos a partir das amostras que permaneceram na cura úmida, e para a comparação de resultados entre os ambientes de exposição, serão apresentados e discutidos os resultados referentes à leitura na idade de 180 dias. A absorção de água na leitura de 3 e 72 horas de ensaio para as amostras nas diferentes idades, assim como a altura da ascensão da água são apresentadas nas Tabela 3 e 4, e a apresentação gráfica nas Figura 1 e 2.

Tabela 3 - Capilaridade - absorção às 3 h nas idades para c.p. câmara úmida $\left(\mathrm{g} / \mathrm{cm}^{2}\right)$

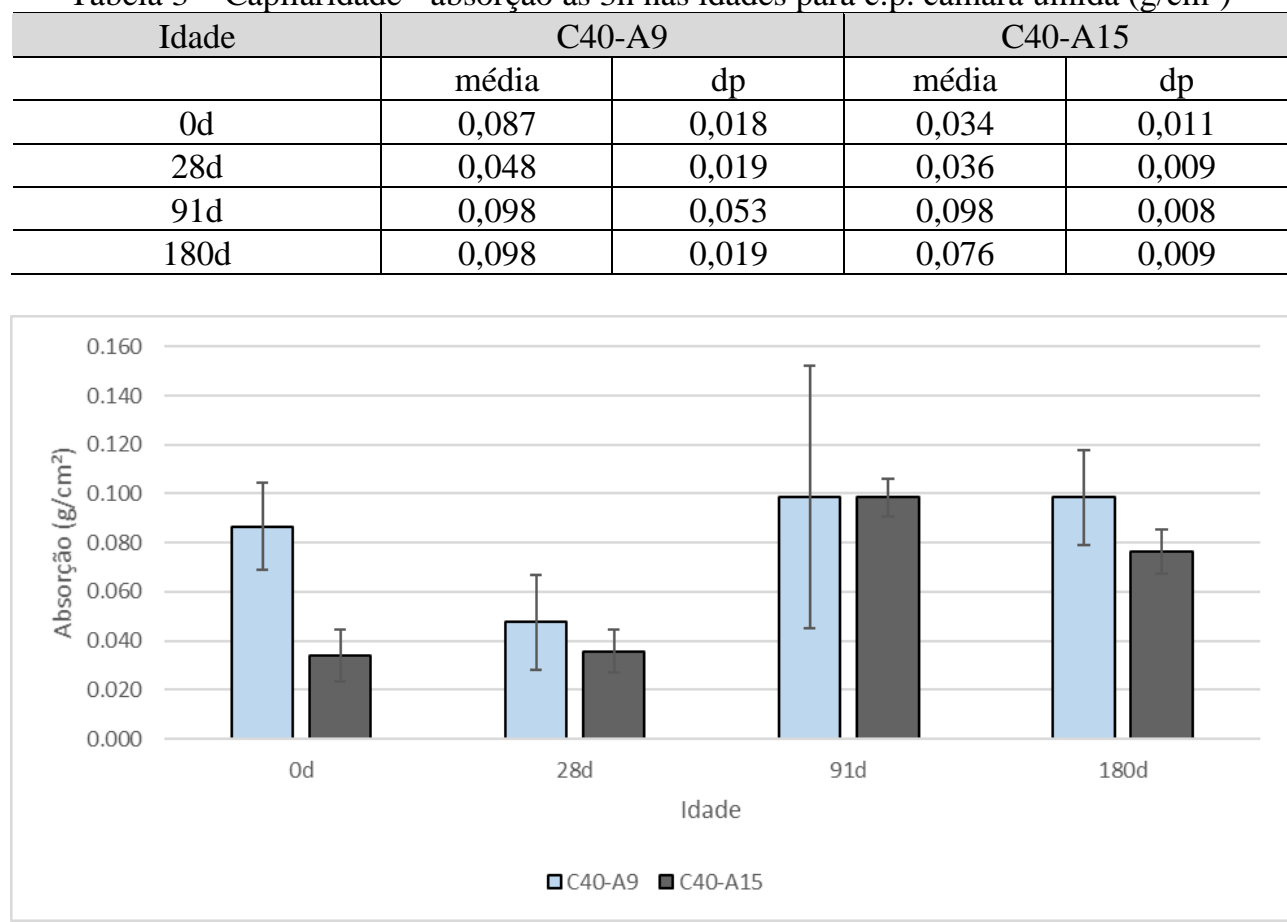

Figura 1: Capilaridade - Absorção às 3h nas idades $\left(\mathrm{g} / \mathrm{cm}^{2}\right)$ 
Tabela 4 - Capilaridade - absorção às $72 \mathrm{~h}$ nas idades para c.p. câmara úmida $\left(\mathrm{g} / \mathrm{cm}^{2}\right)$.

\begin{tabular}{c|c|c|c|c|c|c}
\hline Idade & \multicolumn{3}{|c|}{ C40-A9 } & \multicolumn{3}{c}{ C40-A15 } \\
\hline & média & $\mathrm{dp}$ & altura $(\mathrm{cm})$ & média & $\mathrm{dp}$ & altura $(\mathrm{cm})$ \\
\hline 0d & 0,183 & 0,009 & 2,1 & 0,143 & 0,028 & $*$ \\
\hline 28d & 0,158 & 0,022 & 9,6 & 0,141 & 0,037 & $*$ \\
\hline 91d & 0,188 & 0,054 & 9,2 & 0,236 & 0,016 & 8,5 \\
\hline 180d & 0,253 & 0,039 & 2,4 & 0,243 & 0,019 & 1,5 \\
\hline
\end{tabular}

*Não foi possível identificar a altura da ascensão de água nos corpos de prova rompidos

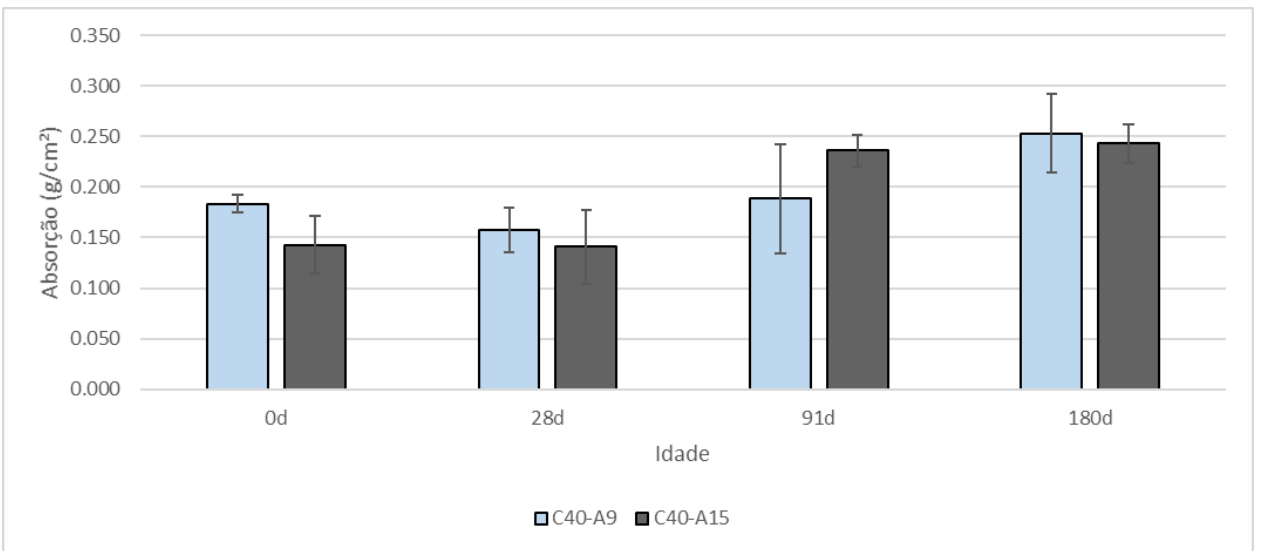

Figura 2: Capilaridade - Absorção às $72 \mathrm{~h}$ nas idades $\left(\mathrm{g} / \mathrm{cm}^{2}\right)$
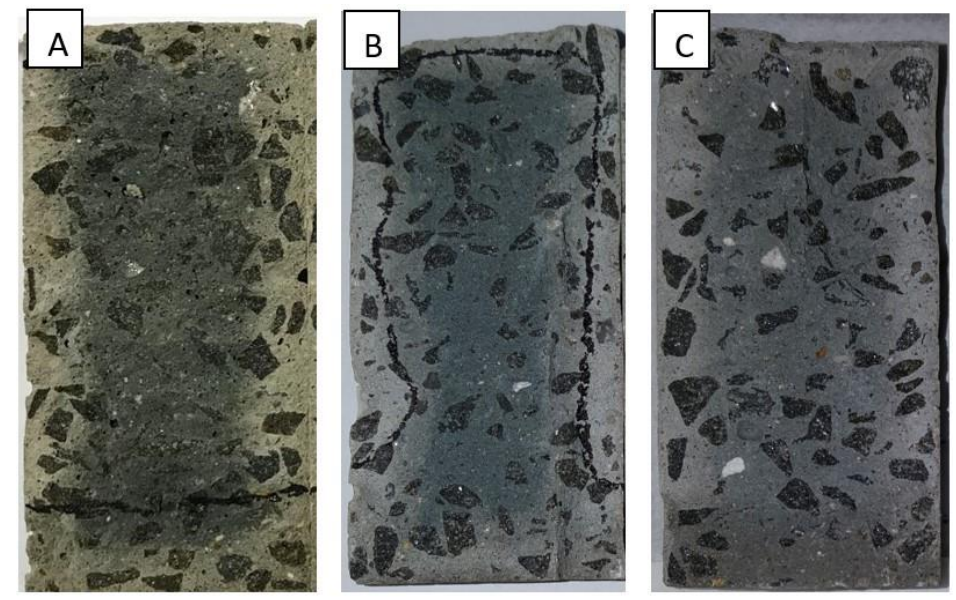

Figura 3: Capilaridade C40-A9 - altura de ascensão de água (A em 0d; B em 28d; C em 180d)
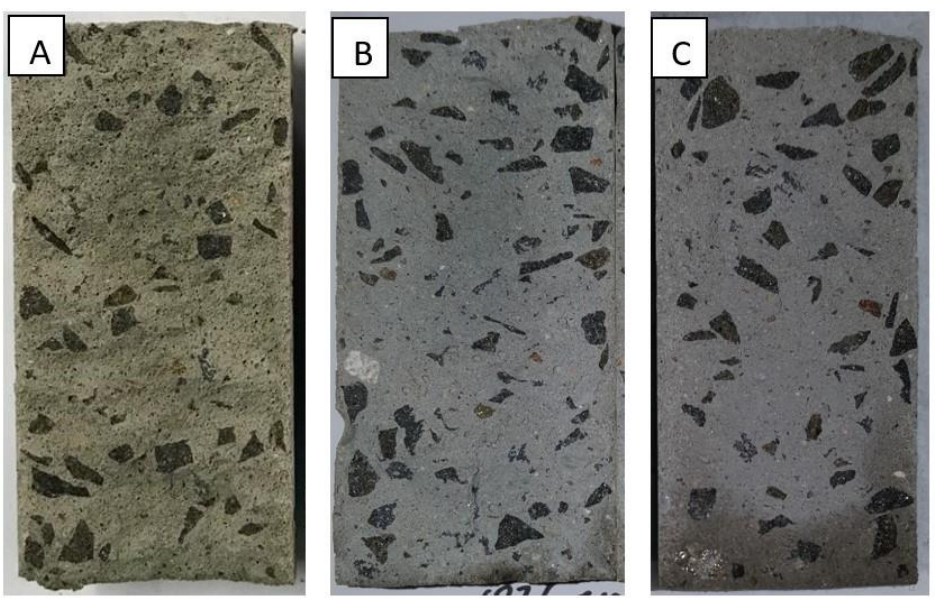

Figura 4: Capilaridade C40-A15 - altura de ascensão de água (A em 0d; B em 28d; C em 180d) 
A altura da ascensão de água teve sua leitura prejudicada, pois mesmo utilizando lanterna para visualizar os limites da ascensão, não foi possível identificá-la em alguns casos, mesmo seguindo o procedimento estabelecido na norma regulamentadora do ensaio (ABNT, 2012). Quando foi possível realizar a leitura da altura da ascensão de água nos corpos de prova, verificou-se uma diferença expressiva entre as idades para as amostras, variando de $2 \mathrm{a} 9 \mathrm{~cm}$. Tal fato se dá pois a altura de ascensão de água se misturou com a coloração no interior do concreto, o que dificultou a leitura da altura máxima, conforme pode ser visto nas Figuras 3 e 4. Portanto, considera-se para fins de avaliação quantitativa apenas os resultados de absorção de água, pois o resultado é menos suscetível a erros relacionados ao operador.

É comum encontrar na literatura resultados de absorção de água por capilaridade para concretos convencionais na ordem de $1 \mathrm{~g} / \mathrm{cm}^{2}$. Porém, nos experimentos de Assié, Escadeillas e Waller (2007), onde foi avaliada a durabilidade de traços de concreto autoadensável, no traço de resistência característica à compressão de $40 \mathrm{MPa}$ foi obtido o valor médio de $0,264 \mathrm{~g} / \mathrm{cm}^{2}$ para a absorção de água por capilaridade às $24 \mathrm{~h}$ (tempo limite do ensaio apresentado no estudo). Portanto, apesar de os valores serem inferiores aos de outros tipos de concreto, a absorção de água por capilaridade determinada nas amostras do presente estudo apresentaram comportamento similar ao apresentado no estudo dos autores citados, com valores de absorção médios variando entre $0,141 \mathrm{~g} / \mathrm{cm}^{2}$ e $0,253 \mathrm{~g} / \mathrm{cm}^{2}$.

De acordo com Ribeiro et al. (2014), quanto menores forem os capilares e menor a interferência das bolhas de ar incorporado, maior será a velocidade de absorção de água, pois as tensões que influem na velocidade aumentam. Para analisar esta informação, buscou-se entender o quanto a absorção nas 3 primeiras horas de ensaio representam no total absorvido em $72 \mathrm{~h}$, em termos de porcentagem. Os resultados dessa relação são apresentados na Tabela 5 e Figura 5.

Tabela 5 - Capilaridade - absorção de água às 3h em relação ao total para c.p. câmara úmida $\left(\mathrm{g} / \mathrm{cm}^{2}\right)$

\begin{tabular}{c|c|c}
\hline Idade & C40-A9 & C40-A15 \\
\hline $0 \mathrm{~d}$ & $47 \%$ & $24 \%$ \\
\hline $28 \mathrm{~d}$ & $30 \%$ & $25 \%$ \\
\hline $91 \mathrm{~d}$ & $52 \%$ & $42 \%$ \\
\hline $180 \mathrm{~d}$ & $39 \%$ & $31 \%$ \\
\hline
\end{tabular}

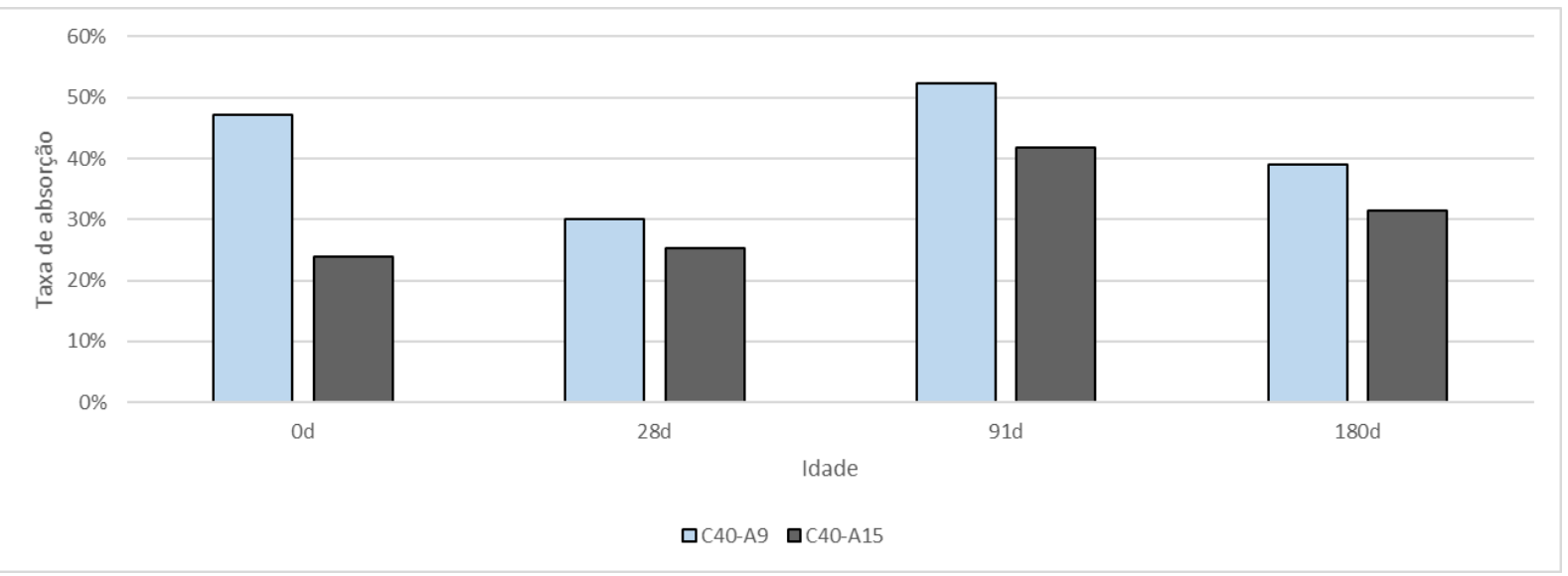

Figura 5: Capilaridade - absorção às 3h vs 72h

Observa-se que em todas as idades, o traço C40-A9 possui uma taxa de absorção em 3 horas maior que o C40-A15, quando referenciados na absorção de água média de cada traço. Tal observação comprova o que é visto em bibliografia.

Por fim, foi analisada a influência dos ambientes de exposição na absorção de água por capilaridade aos 180 dias. Dado que o processo de carbonatação colmata os poros presentes no concreto, a capilaridade deveria ser afetada diminuindose a absorção conforme diminui-se a quantidade de vazios disponíveis para a água ocupar (RIBEIRO et al., 2014). Logo, deve-se observar uma decrescente de absorção, sendo o maior valor referente ao ambiente de laboratório, seguido pelos corpos de prova presentes no ambiente de câmara de $\mathrm{CO}_{2}$ e, com uma menor absorção para aqueles que permaneceram em câmara úmida. Os resultados podem ser visualizados nas Figuras 6 e 7.

O traço C40-A9 não seguiu o esperado, tendo a maior absorção de água em números absolutos para os corpos de prova que permaneceram na câmara de carbontação. Já o C40-A15, para números absolutos, seguiu conforme Ribeiro et al. (2014) indicam. 


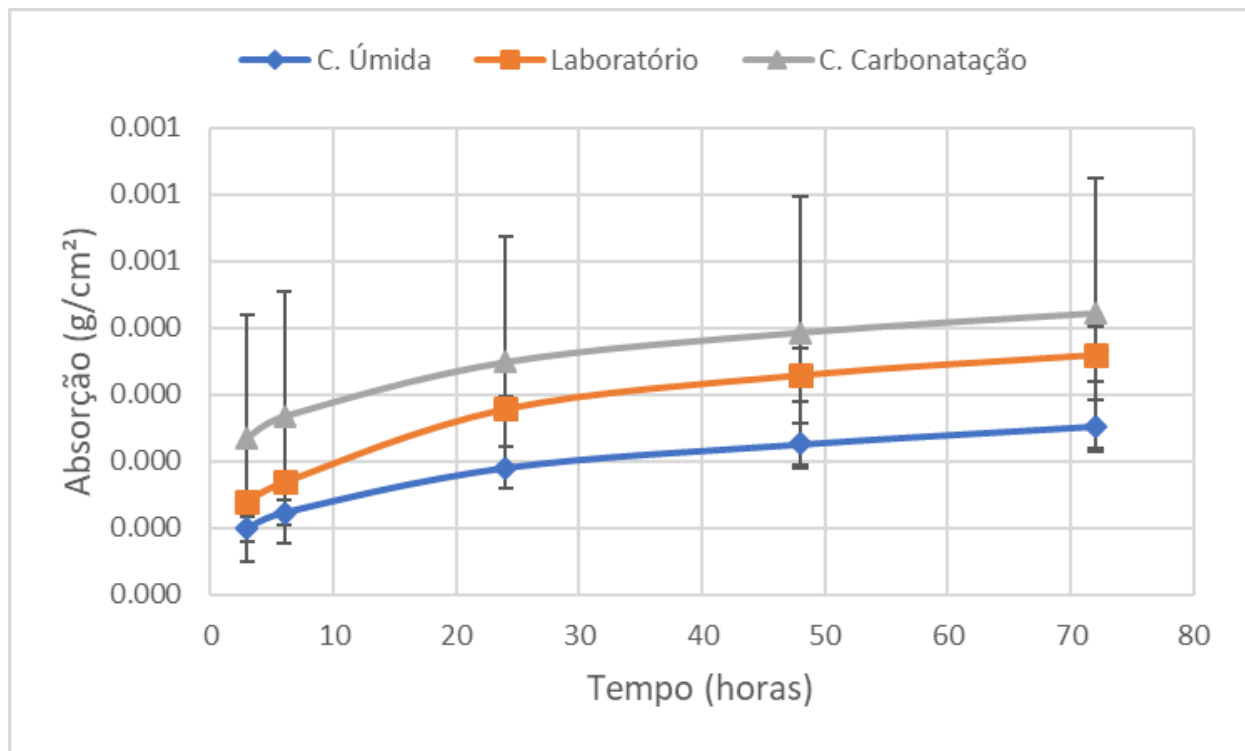

Figura 6 - Capilaridade C40-A9 ambientes 180d.

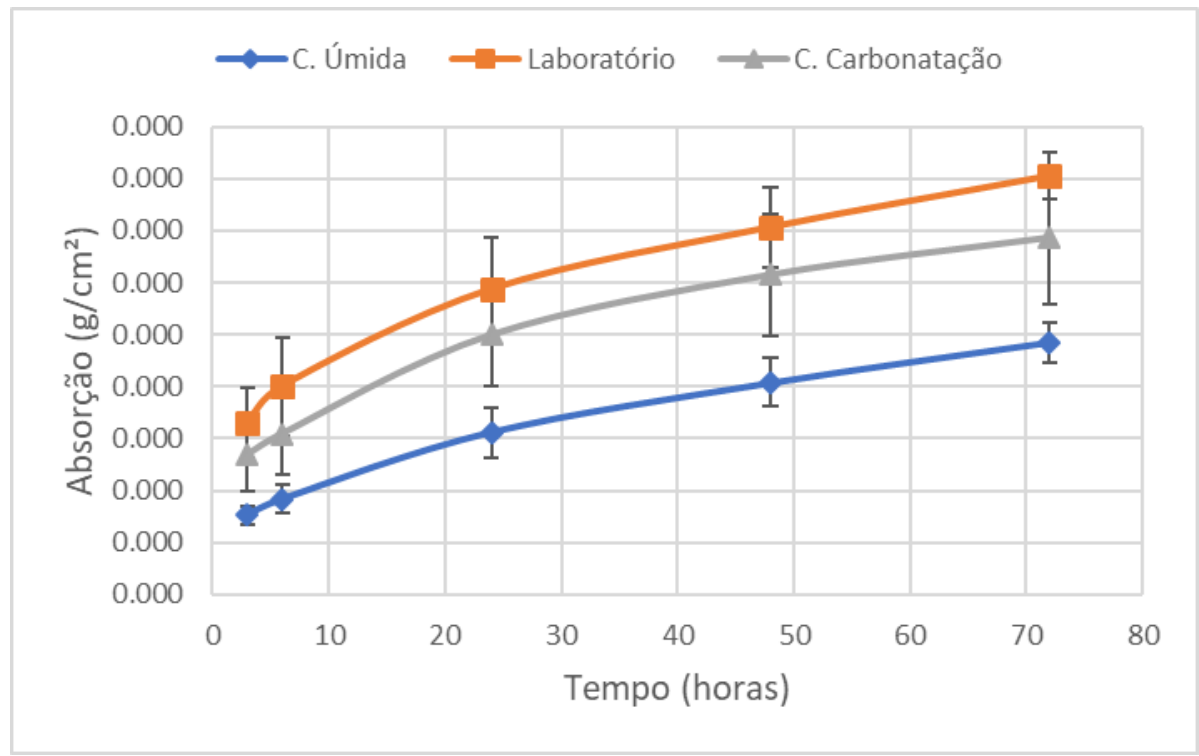

Figura 7 - Capilaridade C40-A15 ambientes 180d.

\subsection{Profundidade de carbonatação}

Para a leitura de profundidade de carbonatação, considerando os diferentes ambientes e tempos de exposição, foram utilizados dois corpos de prova rompidos diametralmente com solução de fenolftaleína aspergida sobre a superficie fraturada para as idades de 28 e 180 dias, enquanto para a idade de 91 dias apenas um corpo de prova foi utilizado, porém aplicando a mesma metodologia de ensaio.

Segundo Bauer (2000), a profundidade de carbonatação, após uma certa taxa de penetração e deposição dos produtos nos poros do concreto, tende a ser estabilizada devido ao fechamento dos poros pelo próprio produto formado. Então, espera-se que nos corpos de prova expostos ao ambiente de câmara de $\mathrm{CO}_{2}$ dê para visualizar este fenômeno, dado que é simulado um tempo extenso em um ambiente de alta agressividade. Além disso, espera-se que devido à incorporação de ar e os resultados já apresentados quanto à permeabilidade e capilaridade, que o traço com $15 \%$ de ar incorporado tenha profundidade de carbonatação maior que o com $9 \%$. As médias e desvios padrão, assim como a visualização gráfica, são apresentados na Tabela 6 e Figura 8 para o traço C40-A9. 
Tabela 6 - Profundidade de carbonatação C40-A9 ambientes-idade (mm).

\begin{tabular}{c|c|c|c|c}
\hline Idade & \multicolumn{2}{|c|}{ C40-A9 - Lab } & \multicolumn{2}{c}{ C40-A9 - Cam } \\
\hline & média & $\mathrm{dp}$ & média & $\mathrm{dp}$ \\
\hline $0 \mathrm{~d}$ & 0,00 & 0,00 & 0,00 & 0,00 \\
\hline 28d & 0,79 & 0,20 & 0,88 & 0,41 \\
\hline 91d & 1,55 & 0,42 & 2,33 & 0,56 \\
\hline $180 \mathrm{~d}$ & 1,82 & 0,37 & 1,61 & 0,69 \\
\hline
\end{tabular}

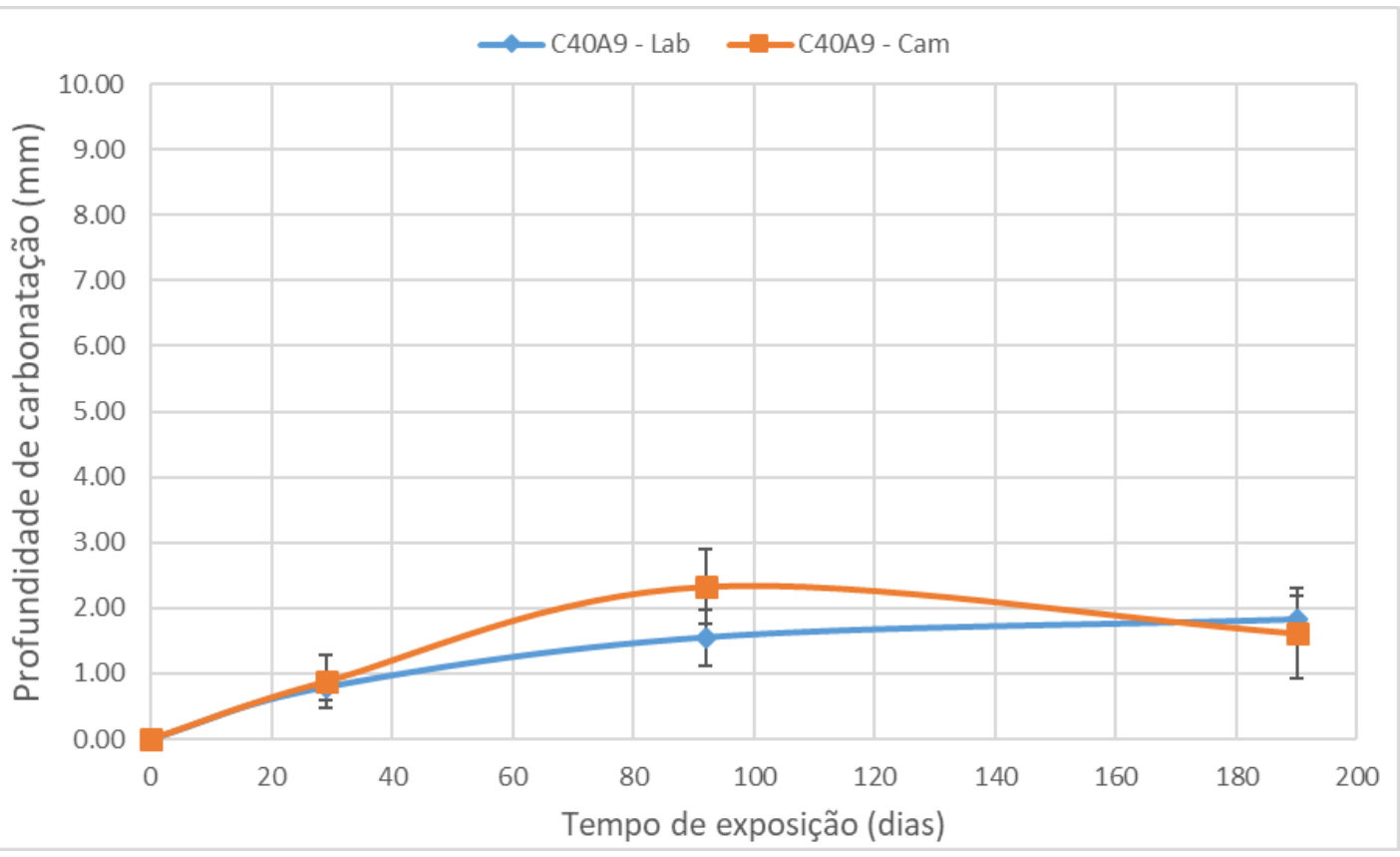

Figura 8 - Profundidade de Carbonatação Ambientes C40A9.

A diferença entre a profundidade de carbonatação observada nos corpos de prova expostos ao ambiente de laboratório e ao ambiente de câmara não é significativa em nenhuma das idades analisadas para o traço de incorporação de ar de $9 \%$.

Quando submetido à analise visual (Figura 9), os corpos de prova do traço C40-A9 rompidos apresentam frente de carbonatação bem definida e sem indícios de comunicação tridimensional generalizada entre os poros. A profundidade média de carbonatação aos 180 dias aferida para ambos os ambientes é muito próxima, e a carbonatação que ocorreu pode ter sido ocasionada por irregularidades superficiais nas amostras analisadas. Dado que no intervalo de tempo considerado na análise não houve diferença significativa entre as profundidades de carbonatação para os ambientes, bem como as profundidades medidas são pequenas (Tabela 6), considera-se que o traço C40-A9 apresentou resistência à carbonatação para o tempo de exposição considerado, mesmo com o alto teor de ar incorporado à mistura.
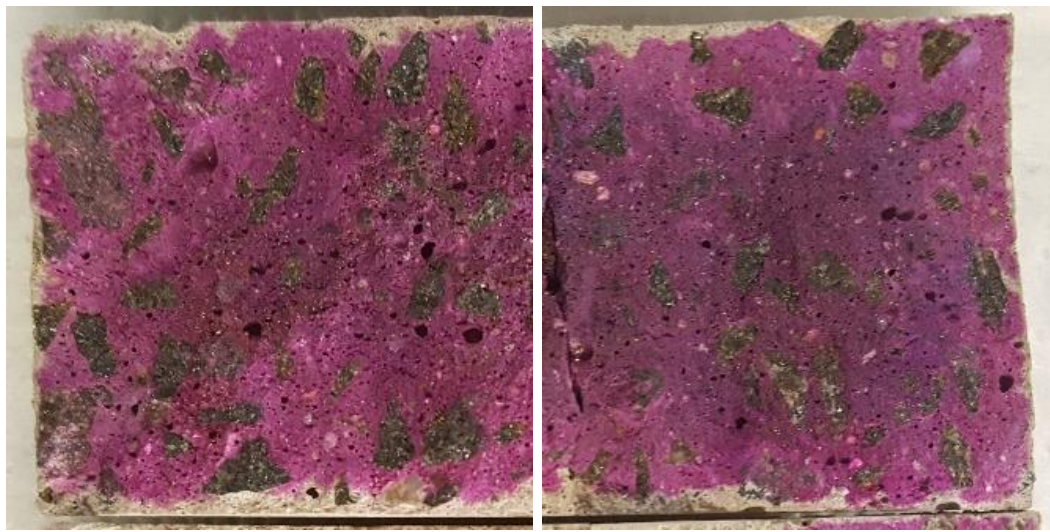

Figura 9 - C40-A9 Lab (esquerda) e Câm (direita) aos 180 dias. 
Por fim, o traço C40-A15 foi analisado com base na leitura de profundidade de carbonatação em diferentes idades. As médias e desvios padrão, assim como a visualização gráfica são apresentados na Tabela 7 e Figura 10.

Tabela 7 - Profundidade de carbonatação C40-A15 ambientes-idade (mm).

\begin{tabular}{c|c|c|c|c}
\hline Idade & \multicolumn{2}{|c|}{ C40-A15 - Lab } & \multicolumn{2}{c}{ C40-A15 - Cam } \\
\hline & média & $\mathrm{dp}$ & média & $\mathrm{dp}$ \\
\hline $0 \mathrm{~d}$ & 0,00 & 0,00 & 0,00 & 0,00 \\
\hline $28 \mathrm{~d}$ & 2,04 & 0,59 & 4,59 & 0,92 \\
\hline $91 \mathrm{~d}$ & 2,91 & 0,64 & 7,38 & 1,09 \\
\hline $180 \mathrm{~d}$ & 5,00 & 0,86 & 7,49 & 1,25 \\
\hline
\end{tabular}

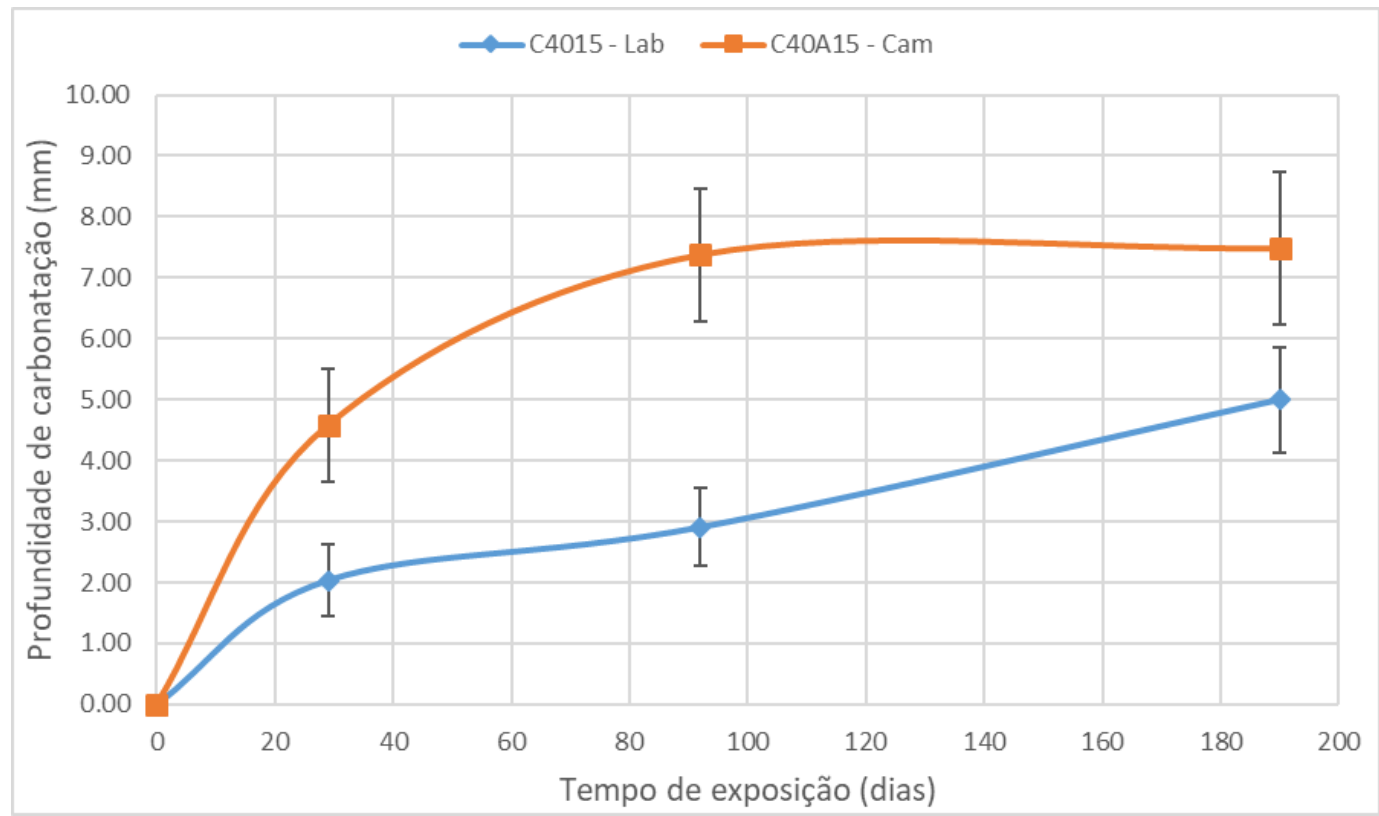

Figura 10: Profundidade de Carbonatação Ambientes C40A15

Neste caso, para o C40-A15, a diferença entre os ambientes é significativa em todas as idades. Seguindo também o que é proposto por Bauer (2000), as amostras de C40-A15 que permaneceram em ambiente acelerado apresentaram tendência de estabilização quanto à profundidade da frente de carbonatação após 90 dias de exposição (Figura 10).

Em análise visual das amostras do traço C40-A15 rompidas (Figura 11), percebe-se que a frente de carbonatação não é tão bem limitada quanto no traço C40-A9. Esta se apresenta de maneira esparsa com diversos pontos mais profundos no concreto, sem aparente continuidade linear no plano de rompimento do corpo de prova. Analisa-se, portanto, que a cadeia de poros existente se comunica tridimensionalmente de maneira generalizada. Em ambos os ambientes foi observada essa comunicação, porém naquele exposto ao ambiente acelerado isso ocorreu de maneira mais acentuada. Zhang et al. (2018) obtiveram resultados similares ao C40-A9 em suas amostras de concreto com teores moderados de ar incorporado (4-5\% de incorporação de ar) e resultados similares ao C40-A15 em suas amostras de altos teores de ar incorporado (7-10\% de ar incorporado), evidenciando que o incremento excessivo de ar incorporado prejudica a microestrutura do concreto com a sobreposição de bolhas de ar e, assim, facilitando a migração de agentes agressivos ao seu interior. 

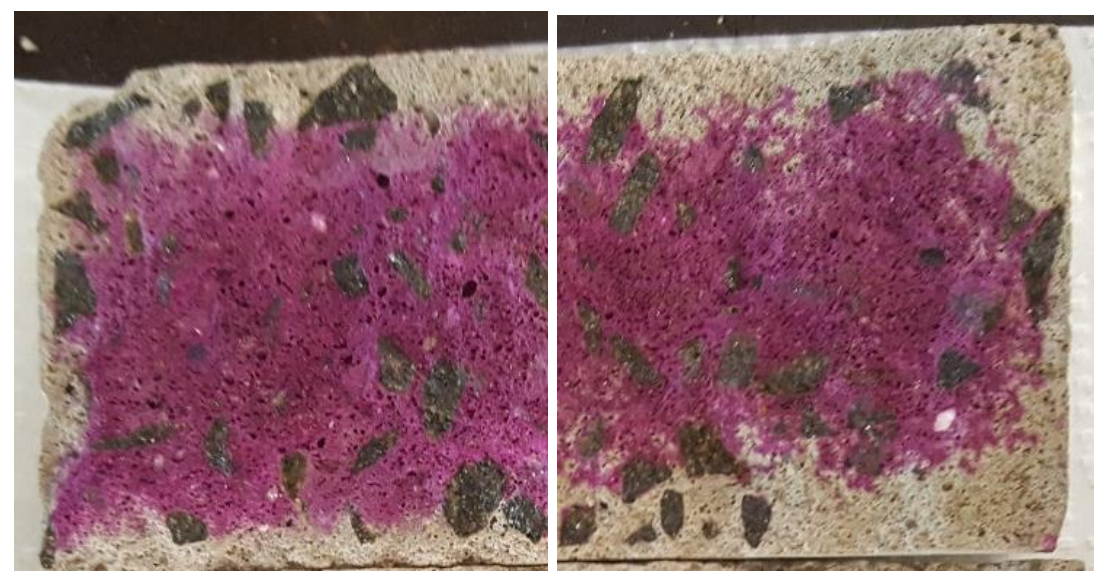

Figura 11: C40-A15 Lab (esquerda) e Cam (direita) aos 180 dias

A diferença entre a profundidade média do traço quando sujeito ao ambiente natural para o traço que permaneceu em ambiente acelerado é de aproximadamente 50\% mais profunda para o segundo ambiente. Ao analisar a profundidade máxima, para o ambiente de laboratório aos 180 dias, foi observada uma profundidade máxima de $9,73 \mathrm{~mm}$ e para a câmara de carbonatação de $18,99 \mathrm{~mm}$, uma diferença de aproximadamente $95 \%$. Tal resultado demonstra que a qualidade de acabamento superficial já não interfere mais na resistência à penetração do agente agressivo (como ocorreu no traço anterior), mas a comunicação dos poros sim tem influência direta no resultado. De acordo com Dolch (1995) e Bauer (2000), as bolhas de ar, por conta do aditivo tensoativo (aditivo incorporador de ar) deveriam ter sua estabilidade superficial elevada e, com isso, minimizar a ocorrência de união ou rompimento das mesmas. Porém, pode-se observar que os poros de ar incorporado estão intercomunicantes no traço C40-A15. Nota-se que, ao quase dobrar o teor de ar incorporado de um traço para o outro, a estabilidade fornecida por relações intermoleculares do tensoativo é suprimida e toda a cadeia de poros intercomunicantes é generalizada no concreto, assim como ocorreu nos estudos de Singh e Singh (2016) e Zhang et al. (2018).

\section{CONCLUSÃO}

Frente aos resultados obtidos para ambos os traços, pôde-se observar que a incorporação de ar afeta de maneira significativa a estrutura de poros presente no concreto de maneira a prejudicar sua durabilidade frente à ação do $\mathrm{CO}_{2}$. Mesmo em uma mistura com baixa relação água/cimento $(0,45)$ e com utilização de empacotamento de grãos para otimização, houve o prejuízo relacionado à comunicação tridimensional dos poros no traço C40-A15, de modo que no período de tempo analisado já foi possível observar a penetração do agente agressivo de maneira não planar (frente de carbonatação bem delimitada) mesmo em ambiente natural. Por outro lado, o traço C40-A9 se mostrou apto a ser utilizado do ponto de vista de durabilidade, pois manteve-se íntegro e, em apenas sua camada superficial, ocorreu a carbonatação do concreto.

Observa-se que, ao utilizar a mesma base de referência para a produção de ambos os traços, a única variável que os diferencia é o teor de ar incorporado. Para obterem resultados tão diferentes do ponto de vista visual e numérico, existe um limite onde a incorporação passa a ser prejudicial, que no caso analisado se situa entre $9 \%$ e $15 \%$. As normas vigentes que se referem ao concreto estrutural não limitam o teor de ar incorporado, também não citam a relação direta da porosidade e estrutura dos poros com a durabilidade. Conclui-se, portanto, que para prosseguir no avanço normativo que diz respeito à durabilidade do concreto armado deve-se ter atenção especial à estrutura dos poros do concreto.

\section{AGRADECIMENTOS}

À USP pela oportunidade de participação do Programa Unificado de Bolsas, em especial ao Departamento de Engenharia de Estruturas da Escola de Engenharia de São Carlos. À UFSCar, em especial ao Laboratório de Materiais e Componentes da Construção Civil do Departamento de Engenharia Civil por ceder o uso da câmara de carbonatação. E também às empresas GCP Applied Technologies, LafargeHolcim e Elkem pela doação dos materiais utilizados. 


\section{REFERÊNCIAS}

ASSIÉ, S; ESCADEILLAS, G; WALLER, V. Estimates of self-compacting concrete 'potential' durability. Construction And Building Materials. p. 1909-1917. out. 2007.

ASSOCIAÇÃO BRASILEIRA DE NORMAS TÉCNICAS (ABNT). NBR 9833: Concreto fresco - Determinação da massa específica, do rendimento e do teor de ar pelo método gravimétrico. Rio de Janeiro. 2008.

. NBR 15823-1: Concreto autoadensável - Parte 1: Classificação, controle e recebimento no estado fresco. Rio de Janeiro. 2017.

. NBR 15823-2: Concreto autoadensável - Parte 2: Determinação do espalhamento, do tempo de escoamento e do índice de estabilidade visual - Método do cone de Abrams. Rio de Janeiro. 2017.

. NBR 15823-3: Concreto autoadensável - Parte 3: Determinação da habilidade passante - Método do anel J. Rio de Janeiro. 2017.

. NBR 15823-4: Concreto autoadensável - Parte 4: Determinação da habilidade passante - Métodos da caixa L e da caixa U. Rio de Janeiro. 2017. Janeiro. 2017.

. NBR 15823-5: Concreto autoadensável - Parte 5: Determinação da viscosidade - Método do funil V. Rio de

. NBR 15823-6: Concreto autoadensável - Parte 6: Determinação da resistência à segregação - Métodos da coluna de segregação e da peneira. Rio de Janeiro. 2017.

BERTOLINI, L. Materiais de construção: patologia, reabilitação, prevenção. São Paulo: Oficina de Textos, 2010. $414 \mathrm{p}$.

BAUER, L. A. F. Materiais de construção. Rio de Janeiro: LTC, 2000. 1 v.

DE SOUZA, V. C. M.; RIPPER, T. Patologia, recuperação e reforço de estruturas de concreto. São Paulo: Pini, 2009.

DOLCH, W. L. Concrete admixtures handbook: properties, science and technology. New Jersey: Noyes Publications, 1995, p. 518-557.

FERREIRA, F. M. M. Influência da incorporação de ar em concreto autoadensável para paredes de concreto moldadas no local. 2019. 195 p. Dissertação (Mestrado). Escola de Engenharia de São Carlos, Universidade de São Paulo, São Carlos. 2019.

GOMES, P. C. C.; BARROS, A. R. Métodos de dosagem de concreto autoadensável. São Paulo: PINI, 2009, 165p.

ISAIA, G. C. et al. Concreto: Ciência e Tecnologia. São Paulo: Ibracon, 2011. 1 v.

MEHTA, P. K.; MONTEIRO, P. J. M. Concreto: microestrutura, propriedades e materiais. 2.ed. São Paulo: IBRACON, 2014.

OLLIVIER, J. et al. Durabilidade do Concreto: Bases científicas para a formulação de concretos duráveis de acordo com o ambiente. São Paulo: Ibracon, 2014. 615 p.

RIBEIRO, D. V. et al. Corrosão em estruturas de concreto armado: teoria, controle e métodos de análise. Rio de Janeiro: Elsevier, 2014.

ROCHA, G. L.; FERREIRA, F. G. S.; CASTRO, A. L. Avaliação do comportamento de concreto autoadensável com aditivo incorporador de ar frente à ação da carbonatação. In: CONGRESSO BRASILEIRO DO CONCRETO, 61., 2019, Fortaleza. Anais... . Fortaleza: Ibracon, 2019. v. 1, p. 1 - 16. 


\section{CBPAT 2020 ANAIS \\ CONGRESSO BRASILEIRO DE PATOLOGIA DAS CONSTRUÇÕES \\ DE 15 A 17 DE ABRIL | FORTALEZA - CE \\ ISBN 978-65-86819-05-2

SINGH, S. P.; SINGH, N. Reviewing the Carbonation Resistance of Concrete. Journal of Materials And Engineering Structures. p. 35-57. maio 2016

ZHANG, P. et al. Effect of Air Entrainment on the Mechanical Properties, Chloride Migration, and Microstructure of Ordinary Concrete and Fly Ash Concrete. Journal of Materials in Civil Engineering, [s.1.], v. 30, n. 10, p. 04018265.1-04018265.9. out. 2018. American Society of Civil Engineers (ASCE). doi: 10.1061/(asce)mt.19435533.0002456 